\title{
REY Y «TOTALIDAD NACIONAL» EN LA OBRA DE DON DUARTE: EN TORNO A LOS CONCEPTOS DE PRUDENCIA Y CONSEJO
}

\author{
Armando Luís de CaRvalho Homem \\ Universidad de Oporto \\ ISABEL BECEIRO PITA \\ Instituto de Historia. CCHS (CSIC)
}

RESUMEN: En el marco de lo que podemos designar como «orígenes intelectuales del Estado Moderno» ha sido examinada reiteradamente la posición del individuo frente a la «teocracia», la feudalidad, el derecho común romano-canónico y las ideas politicas de fines de la Edad Media. En el presente trabajo se procede a una prospección de la problemática de lo «individual» y de lo «social/nacional» en la obra de D. Duarte el Elocuente (1391-1438, rey a partir de 1433), no tanto al nivel del ideario -ya suficientemente abordado- como del léxico, analizando las apariciones de los términos "prudéncia» $y$ "conselho» en el "Leal Conselheiro» y en el "Livro da Cartuxa».

Palabras Clave: Poder regio. Comunidad política. Reino. Ideas políticas. Portugal. Siglo XV.

ABSTRACT: When surveying the intellectual origins of the Modern State, there has been continued interest with regards to the position of the «individual» in relation to "teocracy", "feudality, Sage Rights» and late Medieval political ideas. This study will examine the problem of «individual» and "social / national» in the works of King Edward, "the Eloquent» (1391-1438, king since 1433), by analysing the context and frequency with which the words "prudência» (prudence) and "conselho» (counsel) occur in "Leal Conselheiro» and «Livro da Cartuxa».

KeY WORds: Regal Power. Political community. Kingdom. Political ideas. Portugal. 15th century. 


\section{CONSIDERACIONES PREVIAS}

Como es sabido, los años 80 y 90 del siglo pasado (1984-1997), asistieron al desarrollo, bajo la responsabilidad sucesiva del Centre National de la Recherche Scientifique (CNRS, Francia) y de la European Science Foundation (ESF) ${ }^{1}$, de una serie de estudios programados en torno a las problemáticas de la Génese $e^{2}$ Origenes $^{3}$ del Estado Moderno en Europa (ss.. XIII-XVIII) ${ }^{4}$. Al culminar unas buenas decenas de reuniones científicas, el programa de la ESF llegó a su fin con la publicación de siete volúmenes colectivos —editados en versiones inglesa y francesa- en torno a otros tantos ejes temáticos: 1) Estado y guerras ;2) sistemas económicos / finanzas / fiscalidad ${ }^{6}$; 3) legislación / justicia / instrumentos legales del poder ${ }^{7}$ 4) élites, poder y construcción del Estado ${ }^{8}$; 5) representación / resistencias / sentimientos de pertenencia nacional ${ }^{9}$; 6) iconografía / legitimación / propaganda ${ }^{10}$; 7) el individuo en la teoria y en la praxis ${ }^{11}$.

1 Sobre estas dos iniciativas y sus consecuencias, cf. Blockmans, W.; Genet, J.-Ph.; MuhlBerg, C.: «Annexe I: The Origin of the Modern State (Activité additionnelle de la European Science Foundation)», en GENET, Jean-Philippe, (ed.): L 'État Moderne: genèse. Bilans et perspectives, Paris, CNRS, 1990, pp. 285-303.

2 Terminologia del CNRS.

3 Terminologia de la ESF.

4 Tal vez la mayor empresa historiográfica colectiva desde que existen historiadores profesionales: cf. «Presentación», in Aragón en la Edad Media. El Estado en la Baja Edad Media: nuevas perspectivas metodológicas, Sesiones de trabajo. V Seminario de Historia Medieval, Zaragoza, universidad de Zaragoza / Facultad de Filosofía y Letras, Departamento de Historia Medieval, Ciencias y Técnicas Historiográficas y Estudios Árabes y Islámicos, 1999, p. 5. Sobre la limitada presencia portuguesa en estas iniciativas. cf. el trabajo cit. supra, $\mathrm{n}^{\mathrm{o}}{ }^{1}$, pp. 287-289; el volumen Blockmans, Wim; MACEDo, Jorge Borges de; Genet, Jean-Philippe (Ed.): The Heritage of the PreIndustrial European State, Lisboa, Arquivos Nacionais / Torre do Tombo, 1996; y las consideraciones críticas de Homem, Armando Luís de Carvalho - «Balanço de um Ciclo», texto de clausura de Coelho, Maria Helena da Cruz; Homem, Armando Luís de Carvalho (Coord.): A Génese do Estado Moderno no Portugal Tardo-Medievo (séculos XIII-XV), Lisboa, Universidade Autónoma, 1999, pp.. 411-417, sobre todo las pp. 414 y ss.

5 Contamine, Philippe (dir): Guerre et concurrence entre États, traducción francesa, Paris, PUF, 1996 (col. «Les origines de l'État moderne en Europe», dir. Wim BLOCKMANS; Jean-Philippe GENET).

6 BONNEY, Richard (dir): Systèmes économiques et finances publiques, traducción francesa, Paris, PUF, 1996 (col. «Les origines de l'État moderne en Europe», dir. Wim BlOCKMANS; Jean-Philippe GENET).

7 PADOA-Schioppa, Antonio, (dir.): Justice et Législation, traducción. francesa, Paris, PUF, 2000 (col. «Les origines de l'État moderne en Europe», dir. Wim BLOCKMANS; Jean-Philippe GENET).

8 ReINHARD, Wolfgang, (dir.): Les Élites du pouvoir et la construction de l'État en Europe, trad. franc., Paris, PUF, 1996 (col. «Les origines de l'État moderne en Europe», dir. Wim BlockMans; Jean-Philippe GENET).

9 BLICKLE, Peter (dir.): Résistance, représentation et communauté, trad. franc., Paris, PUF, 1996 (col. «Les origines de l'État moderne en Europe», dir. Wim BlockmANs; Jean-Philippe GENET).

10 Ellenius, Alan, (dir.): Iconographie, propagande et légitimation, trad. franc., Paris, PUF, 1998 (col. «Les origines de l'État moderne en Europe», dir. Wim Blockmans; Jean-Philippe GENET).

11 Coleman, Janet, (dir.): L'Individu dans la théorie politique et dans la pratique, trad. franc., 
En medio de toda esta producción historiográfica, ¿en dónde toma cuerpo lo que podríamos designar como Orígenes intelectuales del Estado Moderno? Quizás, en parte, en los volúmenes que concretan los mencionados ejes 3) 5) 6) y 7). Al final, ¿qué tipo de historia de las ideas políticas presupone la Génesis del Estado Moderno?

Curiosa y significativamente, las síntesis finales no dan gran cuenta de las renovaciones que puedan haberse producido en este campo. En su introducción a la obra más próxima al epicentro de los planteamientos de este artículo, la investigadora inglesa Janet Coleman aborda justamente la cuestión del individuo en el estado medieval ${ }^{12}$ :, a la par de la problemática del redescubrimiento de Aristóteles, o del ideario de santo Tomás de Aquino, de Jean de Paris, de Guillaume de Ockham, de Marsilio de Padua, de Baldo o de Bartolo, para, a partir de ahí, analizar el papel del individuo frente a la teocracia, la feudalidad y el derecho común romano-canónico

Por otro lado, Jean-Philippe Genet, en su síntesis de 1999 sobre las mutaciones en la educación y cultura del Occidente cristiano durante los siglos XII-XV ${ }^{13}$, traza perspectivas renovadas sobre los progresos sociales de la escritura, sobre todo de la escritura pragmática, en sociedades de alfabetización restringida (en el sentido de restricted literacy, concepto tomado de investigadores ingleses de las ciencias sociales, como Jack Goody o Michael Clanchy), la necesidad social del derecho, la emergencia del campo literario y el nacimiento de las literaturas europeas, el humanismo, la creación literaria o los progresos en el dominio de la realidad (por arquitectos, matemáticos...). Sin embargo, en lo que atañe estrictamente a la historia de las ideas, no da prácticamente cuenta de las mutaciones que él mismo protagonizó o ayudó a protagonizar (v. g., en el ámbito de la lexicografía cuantitativa para la interpretación de la literatura política), quedándose en un tratamiento de los textos políticos o teológicos como grandes temas y su difusión en el tiempo (en la línea de Michael Wilks, Percy E. Schrammm, Walter Ullmann, Francisco Elias de Tejada Spínola, José Manuel Nieto Soria o, en Portugal, de Paulo Merêa [1888-1977] o Martim de Albuquerque, por ejemplo). En 2003, la perspectiva de Genet no cambia mucho en el libro derivado de su tesis doctoral ${ }^{14}$, aunque encontremos ahí cuestiones capitales como:

Parlamento/consejo/opinión

Lenguas, escritura y comunicación: el lugar del latín, del francés, del inglés, de las lenguas célticas; textos manuscritos y libro impreso.

Paris, PUF, 1996 (col. «Les origines de l'État moderne en Europe», dir. Wim BLOCKMANS; JeanPhilippe GENET).

12 Ibid., p. 1-42.

13 GenET, Jean-Philippe: La Mutation de l'éducation et de la culture médiévales. Occident chrétien (XII siècle-milieu du XV siècle), 2 vols., Paris, Seli Arslan, 1999.

14 GeNET, Jean-Philippe: La Genèse de l'État moderne. Culture et société politique en Angleterre, Paris, PUF, 2003. 
La aplicación de la teoría de los campos (de Pierre Bourdieu) a la época final de la Edad Media, especialmente a la cuestión del campo literario.

Pero, en el fondo, sólo de pasada nos hablan estas obras del análisis del discurso político en términos lexicográficos, con utilización de métodos cuantitativos (especialmente de un análisis factorial) y de una sofisticada información, aunque materias en las que Genet fue pionero en la referida sofisticación informática — los análisis léxicos — habían sido antes punto fuerte de Bernard Guenée $^{15}$. Es más, algunos de sus discípulos, como Albert Rigaudière ${ }^{16}$, habían proseguido en esta línea a través de numerosos artículos de método, aún cuando se echa en falta una síntesis, ya necesaria

Es un poco esa historia de las ideas políticas en cuanto análisis de vocabulario, lo que proponemos aquí, y necesariamente a una micro-escala, en relación a los textos de D. Duarte (1391-1438) ${ }^{17}$. En una dicotomía entre la individua-

15 Cf. Guenée, Bernard: «La Folie de Charles VI: étude de mots", en IDEM, Un roi et son historien. Vingt études sur le règne de Charles VI et las Chronique du Religieux de Saint-Denis, Paris, Diff. De Bocard, 1999, p. 277-283; IDEM, L'Opinion publique à la fin du Moyen Age d'après la Chronique de Charles VI du Religieux de Saint-Denis, Paris, Perrin, 2002,. especialmente los capítulos 3 y 4, pp. 79 y ss y 93 y ss.

16 Cf. Rigaudière, Albert: «Le Religieux de Saint-Denis et le vocabulaire politique du Droit Romain», en Autrand, Françoise; Gauvard, Claude; Moeglin, Jean-Marie, (ed.): Saint-Denis et la royauté. Études offertes à Bernard Guenée, membre de l'Institut, Paris, Publications de la Sorbonne, 1999, p. 261-298 ; reed. in RigaudièRE, Albert: 2003, Penser et construire l'État en France à la fin du Moyen Âge $\left(X I I I^{e}-X V^{e}\right.$ siècle), Paris, Comité pour l'histoire économique et financière de la France, 2003, p. 323-335.

17 Para el ideario en torno al príncipe del tardo-medievo, véase BEAUNE, Colette: 'Les Structures politiques comparées de l'Occident Médieval (1250-1500)», en FAVIER, Jean (Dir.): XIV et $X V^{\mathcal{R}}$ siècles: crises et genèses, Paris, PUF, 1996, pp. 1-126, especialmente las 21-28; para una contextualización peninsular, NieTo SORIA, José Manuel: "La realeza», en NieTo SORIA, J. M. (Dir.): Orígenes de la Monarquía Hispánica: Propaganda y legitimación (ca. 1400-1520), Madrid, Dykinson, 1999, pp. 25-62; para el caso portugués, BUESCU, Ana Isabel: Imagens do Príncipe. Discurso Normativo e Representação (1525-49), Lisboa, Cosmos, 1996 e SOARES, Nair N. Castro: O Príncipe ideal no século XVI e a obra de D. Jerónimo Osório, Coimbra, INIC/Centro de Estudos Clássicos e Humanísticos, 1994; sobre la obra escrita de D. Duarte, en su conjunto, v.: SimÕES, M, «Duarte, Dom» y LORENZO, R.: "Leal Conselheiro" e "Livro da ensinança de bem cavalgar toda sela"», en Lanciani, Giulia; Tavani, Giuseppe (Coord.): Dicionário da Literatura Medieval Galega e Portuguesa, Lisboa, Caminho, 1993, pp. 222-223, 383-384 e 400-302, respectivamente; sobre el pensamiento filosófico del rey, véase, Gama, José: «A Geração de Avis I, D. Duarte», in Calafate, Pedro (Dir.): História do Pensamento Filosófico Português, I. Idade Média, Lisboa, Caminho, 1999, p. 379-411; sobre la cultura de corte en los albores de la dinastía de Avis, Monteiro, João Gouveia: «Orientações da Cultura de Corte na $1 .^{a}$ metade do século XV. A Literatura dos Príncipes de Avis», Vértice, nueva serie., 5 (1989, Agosto), pp. 89-103; para la biografía del rey, v. DuARTE, Luís Miguel: D. Duarte, Lisboa, Círculo de Leitores, 2006; para su afirmación política antes de 1433, v. Homem, Armando Luís de Carvalho: O Desembargo Régio (1320-1433), Porto, INIC/CHUP, 1990, pp. 245-250; e FreITAS, Judite A. Gonçalves de: A Burocracia do «Eloquente» (1433-1438): os textos, as normas, as gentes, Cascais, Patrimonia, 1996; y sobre su protagonismo en la génesis de las "Ordenações 
lidad del sujeto del poder y la sociabilidad del objeto del poder, hemos escogido dos conceptos importantes en el ideario político de fines de la Edad Media: prudencia y consejo ${ }^{18}$.

¿Qué niveles de ocurrencia, y que contextos, para los respectivos significantes?

Pero antes consignaremos unas breves notas sobre la biografía política e intelectual del monarca.

\section{D. Duarte: Hombre de Poder / Hombre De SABer}

Varón segundogénito del matrimonio de João I con Filipa de Lancaster, D. Duarte nació en Viseu, el 9 de noviembre de 1391. A finales de la década, por el fallecimiento del primogénito Afonso ${ }^{19}$, se convirtió en el heredero de la Corona.

En 1408, las cortes de Évora ${ }^{20}$ deliberaron proceder à la creación de las $C a$ sas de los infantes Duarte, Pedro e Henrique. Entonces el futuro rey pasa a disponer de un rendimiento anual de 8 contos -cantidad equiparable a su equivalente en «cuentos» castellanos, provenientes de la cobranza de las sisas. Dos anos después, João I donó además un significativo montante de rentas y derechos al heredero ${ }^{21}$. A partir de 1411, la Chancelaria régia nos proporciona vastos testimonios de la administración de un abultado patrimonio, traducida en cartas e albalás de la autoria del propio D. Duarte. Ya en 1408 la creación de la Casa le otorgó una suma proveniente de imposiciones públicas iSerá de extrañar que la gestión de D. Duarte acabe por invadir la esfera de goberna-

Afonsinas, v. AlbuQuerQue, Martim de: «O Infante D. Pedro e as Ordenações Afonsinas», Biblos, LXIX (1993), pp.. 157-171; Homem, A. L. de Carvalho: «Législation et compilation législative au Portugal du début du $\mathrm{XV}^{\mathrm{e}}$ siècle: la genèse des Ordonnances d'Alphonse V', en Autrand, Françoise; Gauvard, Claude; MoEglin, Jean-Marie (Ed.): Saint-Denis et la royauté. Études offertes à Bernard Guenée, Membre de l'Institut, Paris, Publications de la Sorbonne, 1999, p. 671-689; IDEM, «Estado Moderno e legislação régia: produção e compilação legislativa em Portugal (séculos XIIIXV)', en Coelho, M. ${ }^{a}$ Helena C.; Homem, A. L. de Carvalho (Coord.): Génese ( $A$ ) do Estado Moderno no Portugal Tardo-Medievo (séculos XIII-XV), Lisboa, Universidade Autónoma, 1999, p. 111130; e IDEM, «Rei e «estado real» nos textos legislativos da Idade Média portuguesa», En la España Medieval, 22 (1999), p. 177-185.

18 Sobre estos conceptos, véase Michaud-QuANTIN, Pierre: Universitas. Expressions $d u$ mouvement communautaire dans le Moyen-Age Latin, Paris, Vrin, 1970, sobre todo el capítulo. 5., p. 129 ss.; y GuENÉE, Bernard, L'Opinion publique à la fin du Moyen Âge..., pp. 79-88 y 93-97.

19 TORRES, Ruy d'Abreu, «Afonso, D. (1390-1400 ?)», en SERRÃO, Joel (Dir.): Dicionário de História de Portugal, reimpr., vol. I, Lisboa / Porto, Iniciativas Editoriais / Livraria Figueirinhas, 1971, p. 34.

20 SERrÃo, Joaquim Veríssimo, Évora, Cortes de (1408)», en SERrÃo, Joel (Dir.): Dicionário de História de Portugal, reimpr., vol. II, Lisboa / Porto, Iniciativas Editoriais / Livraria Figueirinhas, 1971, p. 150.

${ }_{21}$ Véanse estos testimonios en Homem, Armando L. de Carvalho: O Desembargo Régio...,pp. 245-246. 
ción, en principio en los dominios financiero y fiscal, y más tarde también en materias de justicia y defensa del reino? Es decir, según la «vox populi» de los historiadores está desde entonces asociado al poder, posee su Casa y sus oficiales, privados y consejeros. De acuerdo con lo ya expresado por Carvalho Homem, «temos agora lado a lado um Rei prestes a atingir a casa dos 60 anos, em vias de crescente desinteresse pelas fainas governativas, e um Infante que ainda não atingiu os 30 anos» ${ }^{22}$.

Por otro lado, este infante - después rey- se afirmará como el gran protagonista del proceso de recopilación legislativa que culminará en las Ordenações Afonsinas ${ }^{23}$, proceso iniciado en torno a las cortes de Santarem $(1418)^{24}$, que D. Duarte acompaña desde sus comienzos, pero que no verá finalizado en vida. Sólo a mediados de la década de 1440, durante la minoridad de Afonso V y siendo el infante D. Pedro regente del reino, será dada por concluida la primera recopilación portuguesa de leyes regias. Pero en el estado actual de nuestros conocimientos, se puede afirmar que D. Duarte fue el gran protagonista de la empresa y que estuvo presente en ella durante unos 20 años de los cerca de 30 que transcurrieron en su elaboración ${ }^{25}$. No es casual el que el futuro soberano mandara proceder a un compendio de la legislación de los monarcas anteriores a partir de Afonso II, conocido como «Ordenações del-Rei Dom Duarte» ${ }^{26}$. Esta obra, que incluye un índice de materias, realizado por el propio heredero de la corona, figura en el inventario de la biblioteca de su comendatario ${ }^{27}$; y, al contrario de una iniciativa previa ${ }^{28}$, es considerada habitualmente una pieza esencial en el proceso - largo y a veces accidentado- que desemboca en las Ordenações Afonsinas ${ }^{29}$.

En definitiva, la labor de este soberano constituye el mejor exponente de los vínculos que se establecen en este período entre cultura, ideología del poder

\footnotetext{
22 Ibid.., p. 246.

23 Ordenações Afonsinas, livs. I-V, reimpr. da ed. de 1792, Lisboa, Fundação Calouste Gulbenkian, 1984.

24 Rodrigues, Maria Teresa Campos: «Santarém, Cortes de (1418)», in SERrÃo, Joel (Dir.): Dicionário de História de Portugal, reimpr., vol. III, Lisboa / Porto, Iniciativas Editoriais / Livraria Figueirinhas, 1971, p. 767; SousA, Armindo de: As Cortes Medievais Portuguesas (1385-1490), vol. 2. ${ }^{\circ}$, Porto, INIC/CHUP, 1990, p. 268-274.

25 Sobre esta problemática veánse los trabajos de Martim de AlbuQuerque e de Armando L. de Carvalho Homem cits. supra, n. ${ }^{17}$.

26 Ordenações del-Rei Dom Duarte, ed. Martim de Albuquerque; Eduardo Borges Nunes, Lisboa, Fundação Calouste Gulbenkian, 1988; sobre la cronologia de su elaboración y sus manuscritos, veánse también los textos preliminaress de los dos editores, pp. V-XXXIII.

27 Se trata del «liuro das ordenações dos reis», incluido en la relación titulada «Estes são os liuros que tinha el rey dom Duarte». Livro dos Conselhos de el-Rei D. Duarte (livro da cartuxa), ed. João J. Alves DiAs et al., Lisboa, Estampa, 1982, texto 54, p. 207.

28 Nos referimos al «Livro das Leis e Posturas», atribuido a los años finales del siglo XIV; publicado en Livro das Leis e Posturas, ed. Nuno Espinosa Gomes da SILVA; Maria Teresa Campos Rodrigues, Lisboa, Faculdade de Direito / Universidade. de Lisboa, 1971.

29 V.supra, n. ${ }^{24}$
} 
y exaltación de la dinastía reinante ${ }^{30}$. Este «homem sesudo e de claro entendimento, amador de sciencia de que teve grande conhecimento, e non por descurso d'Escollas, mas per continuar d'estudar, e leer por todos livros» en palabras del cronista Ruy de Pina ${ }^{31}$, es quien, siendo infante, encarga a Fernão Lopes la redacción de las primeras crónicas portuguesas, la dedicada a su padre y predecesor y a los monarcas inmediatamente anteriores ${ }^{32}$. En principio, significan la legitimación de los Avís, — que acceden al poder tras una rebelión y la resistencia a aceptar como heredera a la hija de Fernando I-, la línea de continuidad con los últimos reyes de la Casa de Borgoña y la justificación de la ruptura de la legitimidad que encarna Beatriz de Portugal. Esta política del poder en el campo historiográfico fue proseguida por sus sucesores, al menos hasta el mandato de D. João III, y, como es bien conocido, tuvo como frutos la prolongación de las crónicas de reinados hasta el primero de los titulares, Afonso Hentiques, y, en el otro extremo cronológico, hasta los últimos Avís. Por lo tanto, miradas en conjunto, tienen un sentido mucho más amplio: la memoria de la nación portuguesa y la reivindicación de su especificidad en el conjunto peninsular, que no se satisfacía ya con la inclusión de unos pasajes o páginas en las variantes de la Estoria de España alfonsí.

En cuanto a la obra escrita de D. Duarte, tiene una cronología próxima a su afirmación política, es decir, comienza antes de su ascensión a la realeza. Teniendo en cuenta los textos esenciales, se pueden señalar los siguientes, de su autoría o de su iniciativa:

Leal Conselheiro ${ }^{33}$ : Se puede definir como una «guía de filosofía moral aplicada» ${ }^{34}$, Comprende 103 capítulos, en los cuales abunda el tratamiento de pecados, vicios, virtudes y sentimientos individuales. El conjunto muestra una profunda interconexión entre los planos privado y público, en la línea de los tratados adscritos al género De regímine principum ${ }^{35}$.Su relevancia y originalidad reside, básicamente, en dos aspectos: la exposición pormenorizada de las vivencias del «príncipe», que aúna las evocaciones autobiográficas y el análisis de sus problemas anímicos, con una intensidad insólita en los escritos medievales de

30 BeCeiro Pita, Isabel: «Cultura, ideología y mecanismos de gobierno en la dinastía lusa de los Avís», Signo. Revista de Historia de la Cultura Escrita, universidad de Alcalá, no 5 (1998), pp. 9-35.

31 Ruy de Pina, «Chronica do senhor rey D. Duarte», en Crónicas de rui de Pina, ed. de Lopes DE Almeida, M.: Tesouros da Literatura e da História, Lello\&Irmão eds., Porto, 1977, p. 495. Es la primera semblanza de un monarca luso que incluye claramente el saber y la lectura entre susrasgos encomiásticos.

32 Es el cronista Gomes Eanes de Zurara quien da noticia de este encargo en Crónica da tomada de Ceuta, ed. de Reis Brasil, publicações Europa-América, Sintra, 1992, pp. 44-45.

33 Duarte, D.: Leal Conselheiro, ed. Maria Helena Lopes de CASTRO, Lisboa, IN/CM, 1998.

34 Veánse los trabajos de M. SimõES e R. LORENZO cits. supra, n. ${ }^{17}$.

35 MUÑIZ Coelho, Marcio Ricardo: "O Leal Conselheiro e a tradição do espelho de príncipe: considerações sobre o género», en PAMPín BARRAL, Mercedes, y PARRilla García, $\mathrm{M}^{\mathrm{a}}$ Carmen (coords.): Actas del IX Congreso de la Asociación Hispánica de Literatura Medieval, A Coruña, 2005, vol. 2, pp. 81-104. 
este tipo. Por otro lado, hay que resaltar la importancia otorgada a la prudencia, en la doble acepción común a este período e influenciada por la ética aristotélica, de virtud personal y pieza clave en el arte de gobernar. A ella se le dedican cerca de diez capítulos, que constituyen la base de nuestra aproximación a este concepto eduardino.

Livro da ensinança de bem cavalgar toda sela ${ }^{36}$ : tratado de equitación, dividido en siete partes, comportando un total de 60 capítulos. Es el único de esa modalidad elaborado en la península ibérica durante este período, ya que en los otros reinos únicamente se pueden encontrar algunos pasajes en los tratados de albeitería o hipiatría ${ }^{37}$. Responde a la imagen del titular del poder como sumo señor de vasallos y adiestrador de los jóvenes nobles en las tareas caballerescas, dentro de una totalidad educativa más amplia, que abarca también el refinamiento cortesano y la lectura ${ }^{38}$.

Livro dos conselhos del-Rei D. Duarte ${ }^{39}$, de contenido más heterogéneo. Se trata de un registro de consejos enviados al rey, así como de apuntes y notas que éste mandó consignar por escrito. Es también conocido como Livro da Cartuxa, por haber estado depositado en la biblioteca del convento de la cartuja de Scala Coeli (Évora), desde finales del siglo XVI a principios del XIX, momento en el que pasó al archivo de Torre do Tombo. Contiene 96 textos, entre los cuales figura el inventario de la biblioteca regia.

Don Duarte poseía, además, una biblioteca que tiene para los historiadores de la cultura un especial valor, por ser la única representativa de los intereses de la élite de poder laica, a mediados del siglo XV, que ha llegado hasta nosotros, ya que la perteneciente a su hermano, el Santo Infante don Fernando, estaba casi exclusivamente consagrada a materias eclesiásticas, bíblicas y piadosas. Constaba de 85 obras, 20 escritas en latín y 65 en «lingoajem», es decir, en lenguas romances peninsulares. Su contenido era muy variado. Como en toda la cultura medieval, predominaba la temática religiosa, pero se da cabida, igualmente, a los valores caballerescos - encarnados en los tratados de caza, de «arte militar» y el citado compendio de equitación escrito por el soberano; la historia, en una triple vertiente de escritos de autores latinos, crónicas peninsulares y nacionales y relatos semi-fantásticos sobre las cruzadas y la conquista de

36 DuARTE, D.: Livro da ensinança de bem cavalgar toda sela, reimpr. de la ed. de Joseph M. PIEL (1944), Lisboa, IN/CM, 1986.

37 De hecho, D. Duarte remite a los tratados de este tipo para el conocimiento y enseñanza de las dolencias del caballo, de la crianza del animal y de las otras cuestiones que saber «o perfeito cavalgador», Livro da ensinança de bem cavalgar..., II parte, capítulo $2^{\circ}$ e introducción a la III parte, pp. 12 y 14 .

38 Para las formas de abordar los libros según su contenido, la educación y esparcimiento de los jóvenes nobles a través de justas, cacerías, torneos, juegos de cañas y danzas y las lecturas q que éstos deben entregarse, véase ibid., prólogo, I parte, capítulos $2^{\circ}$ y $3^{\circ}$, y IV parte, capítulo 15 , pp. 3, 6-8 y 120-121.

39 Livro dos Conselhos de el-Rei D. Duarte...La relación de libros corresponde al texto 54, pp. 206-208. 
Troya, las obras sobre el significado y origen de la nobleza, la poesía, la ficción castellana y artúrica, la filosofía y retórica greco-romana, los tratados adscritos al ministerio regio, como el De regímine principum, y algunos volúmenes de materias científicas, en concreto, de medicina y astrología ${ }^{40}$.

\section{DOS CONCEPTOS EN LA OBRA EDUARDINA}

\subsection{Prudencia}

Prudencia é conhecimento das cousas que som pera desejar e esquivar, segundo Tulio. Prudencia é ũu juizo da razom per o qual se pode haver conhecimento de bem e de mal, e do que nom é de ũu nem do outro, segundo Origynem»

(Leal Conselheiro, capítulo. 62) ${ }^{41}$.

En principio, esta obra define la prudencia como una de las cuatro «virtudes moraes», a la par que la fortaleza, la justicia y la templanza, reiterada, sobre todo en los capítulos 50 a 59. Evidentemente, tal definición es común a toda la literatura y tratadística bajomedieval. Lo que distingue a los escritos de don Duarte es, como ya se ha dicho, la exposición pormenorizada de las propiedades de esta cualidad y sus aplicaciones prácticas.

A manera de prólogo encontramos en el capítulo 50 del Leal Conselheiro el siguiente pasaje; «[---] posto que estas virtudes a todos perteeçam, aos grandes senhores mais som necessarias, sem as quais suas almas, pessoas, estado e os do seu senhorio seriam em gram perdiçom, consiirando sempre que os reinos nom som outorgados pera folgança e deleitaçom, mas pera trabalhar de spritu e corpo mais que todos $»^{42}$. Esta vinculación entre las virtudes y las cualidades que debe tener el buen gobernante resulta habitual en los discursos políticos medievales sobre el poder. A las referencias expresas de la obra al De regímine principum, Aristóteles y Vegecio, se puede añadir Las siete partidas, donde la prudencia es designada como cordura ${ }^{43}$.

40 Véase a este respecto NAscimento, Aires Augusto do: "As livrarias dos príncipes de Avís», Biblos, vol. LXXIX (1993), pp. 265-287; MARQUES, José: «Livrarias de mão no Portugal medievo», en José $\mathrm{M}^{\text {a }}$ Soto Rábanos (coord.): Pensamiento medieval hispano. Homenaje a Horacio Santiago-Otero, CSIC y Junta de Castilla y León, Madrid, 1998, vol. I, pp. 807-809; BeCEIRO PITA, Isabel: "Cultura, ideología y mecanismos de gobierno...», pp. 13-15 y «Temas y tipos de lectura entre los sectores laicos de la península ibérica (siglos XIII-XV)», en IDEM, Libros, lectores y bibliotecas en la España medieval, edit. Nausicaã, colección Medievalia, no 2 , Murcia, 2007, pp. 530-532.

41 Duarte, D.: Leal Conselheiro, ed. cit., p. 250.

42 DuARTe, D.: Leal Conselheiro, ed. cit., p. 201.

43 "Que virtudes deue ayer el Rey para beuir derechamente, en este mundo, e ser bien acostumbrado

Cordura es la primera delas otras quatro virtudes que diximos enla tercera ley ante desta que ha el Rey mucho menester: para biuir eneste mundo bien derechamente. Ca esta faze verlas cosas, e 
El desarrollo de este concepto aflora en los capítulos siguientes. Así, y antes de nada (capítulo 51), Prudencia/Rei prudente son ideas asociadas a:

I regimiento verdadero, con un correcto saber de los fines de la gobernación

II pero la prudencia puede ser definida a partir de su contrapartida negativa, como lo contrario a una bienaventuranza centrada en las riquezas, en los deleites y placeres corporales o en la abundancia de los bienes de los sentidos, lo que lleva a los señores a ser tiranos y robadores.

III La prudencia es generadora de señores naturales — «naturais senhores»—, que, por estar en posesión de esta cualidad, tienen dominio sobre los siervos, las bestias y las mujeres, como el viejo sobre el mozo. Es decir, se vincula la prudencia a la condición humana, la calidad de hombre libre, el sexo masculino y la experiencia. El hombre prudente es señor y regidor ipso facto («naturalmente»). El capítulo hace referencia, además de a los autores y obras ya citadas, a Platón, Boecio y Juan de Salisbury.

¿Y cuáles son los requisitos necesarios para alcanzar la prudencia? Éste es el asunto del capítulo 52, inspirado básicamente en el De regimine principum, ya citado anteriormente ${ }^{44}$ :

I Poseer capacidad para recordar — «Remembrança das cousas passadas»-, a fin de que pueda extraer enseñanzas de acontecimientos similares sucedidos con anterioridad.

II Ser avisado, previendo lo que ha de acontecer y los medios para lograr sus objetivos tener buen entendimiento y conocer las leyes y costumbres.

III Tener sutileza para hallar los bienes que son convenientes para su pueblo. Implica la necesidad de contar con buenos consejeros que trabajen, junto con el gobernante, en la búsqueda del provecho para la comunidad.

IV La sabiduría, última de estas propiedades, se presenta como una síntesis de todas las anteriores. Gracias a ella, es posible discernir el bien del mal $\mathrm{y}$ regir rectamente.

Las recomendaciones para vivir de acuerdo con esta cualidad, expresadas en el capítulo siguiente ${ }^{45}$, remiten, en principio, a esa triple vertiente del gobierno de sí mismo, la casa y hacienda, y el estado, inspirada en Aristóteles, que aparece en los tratados medievales de ética política. El guardar conciencia alude al

judgar las ciertamente segund son: e pueden ser, e obrar en ellas como deue, e non rebatosamente [.... \. Las siete partidas, glosadas por el licenciado Gregorio Lçopez, ed. Facsçimil de la de Salamanca, 1556, vol. I, Segunda Partida, Título V, ley VIII fol. 13 r-v.

44 DuArTe, D.: Leal Conselheiro, ed. cit., p. 209-211.

45 Ibíd., pp. 262-269. 
cumplimiento de los deberes que el cristiano tiene para con Dios, para llegar a alcanzar la gloria eterna. El mantener y acrecentar honra y estado constituye la manera habitual de designar las obligaciones de los señores y, al mismo tiempo, sus objetivos básicos. Según las consideraciones de don Juan Manuel concernientes al estado de los emperadores, dentro de una visión idealizada sobre los grupos superiores de la sociedad, englobaba el cuidado de sí mismo, unos actos acordes a su condición, el respeto hacia sus iguales y de mayor rango, la magnanimidad para con sus vasallos y súbitos y el rodearse de buenos oficiales ${ }^{46}$.

Otras dos sugerencias completan y subrayan aspectos de la anterior. El vivir en buena disposición y salud evoca el control del cuerpo y la mesura en la alimentación, el sueño, la sexualidad y las actividades cotidianas que debe presidir la vida de todo ser humano, y especialmente la del soberano, de acuerdo con su papel de guía y modelo para su pueblo ${ }^{47}$. En cuanto al gobierno de la casa y hacienda bien y provechosamente, constituyó una de las principales preocupaciones del monarca y su hermano el infante don Pedro, más tarde regente del reino, puesta de manifiesto en varios textos del Livro dos conselhos: varios pasajes de la «Ordenança dos tempos em que auja de despachar e como» están dedicados a las conversaciones mantenidas a diario con los cargos de la administración del reino y sus oficiales privados; la «Hordenança que el rey dom Eduarte fez pera os seus Capellães» traza las normas para el adecuado funcionamiento de la capilla regia, mientras que el infante fija los criterios para determinar los integrantes de su Casa en el «Regimento que fez o infante dom Pedro pera sua casa ser bem gouernada $»^{48}$.

Finalmente, la recomendación de vivir siempre en razonado buen placer y contentamiento significa la contraposición positiva del deleite desordenado, objeto de críticas $^{49}$, pero también alude a la necesidad de que el buen cristiano de poca importancia a sus adversidades y las considere como manifestaciones de la voluntad de Dios, que está más allá del entendimiento del ser humano.

Las conclusiones de estos puntos hacen referencia a la providencia divina, a la discreción, a evitar la autosuficiencia y la autocomplacencia, a dar el máximo de sí, al auto-conocimiento de fuerzas y flaquezas, a estar en virtud y no en

46 Don Juan Manuel, «Libro de los estados», I parte, capítulo LXII, en Don Juan ManUel, Obras completas, vol. I, ed. de José Manuel BlecuA, edit. Gredos, Madrid, 1982, pp. 315-316.

47 Todos estos consejos ocupan un lugar relevante en los tratados gnómicos castellanos, Las siete partidas y en las normas de la corte del mismo reino, a fines de la Edad Media, Véase a este respecto MENJot, Denis: «Enseigner la sagesse. Remarques sur la littérature gnomique castillane du Moyen Âge» y AlLARD, Jeanne: «La naissance de l'etiquette: les regles de vie à la cour de Castille à la fin du Moyen Àge», en Guglelmi, Nilda, y RuCQuOI, Adeline (coords.): El discurso politico en la Edad Media. Le discours politique au Moyen Âge, CONICET\&CNRS, 1995, pp. 228-230 y 11-29, respectivamente.

48 Livro dos conselhos de El-Rei D. Duarte..., [2], pp. 11-21, [55]. pp. 209-213 y [31], pp. 153-155.

49 Don Juan Manuel pone en boca de Julio, el consejero, Al glosar las formas en que el emperador debe guardar su honra y estado que «en todas estas cosas non deue tomar plazer nin deleyte desordenado», «Libro de los estados», en Obras completas, vol. I, ed. cit., p. 316. 
pecado mortal, y a la prevención frente a actitudes contrarias a la norma. La prudencia se encuentra así asociada a la comprensión, cuidado, provecho y circunspección.

El tratamiento de las cualidades anexas deja patente la influencia que tuvo Alonso de Cartagena en la formación cultural de don Duarte. Como es sabido, durante su estancia en la corte lisboeta, en 1421, compuso el Memoriale virtutum, a instancias del entonces heredero de la corona lusa. ${ }^{50}$ Don Duarte reconoce su deuda con este tratado, que es una paráfrasis de la aristotélica Ética a Nicómaco, citándolo entre sus fuentes al iniciar la exposición de las cuatro virtudes cardinales ${ }^{51}$. Es más, toma de esta obra las tres ramificaciones de la prudencia: la eubolia, definida como «dereitura de conselho», que está ligada a individuos diligentes que persiguen un buen fin e intervienen en todas las materias que les atañen; la sinesis, caracterizada como la capacidad de juzgar y escoger atinadamente entre las opciones planteadas, y el gnomi, o aptitud para enfrentar situaciones nuevas y decidir «singularmente fora da ordenança acostumada» ${ }^{52}$. La incorporación por el soberano de estos conceptos procedentes de un texto en latín, acompañada de aclaraciones y comentarios, responde a la imagen de los gobernantes de la dinastía Avís como educadores de los miembros de su corte y, por extensión, de su pueblo, a la que obedecen también las traducciones de escritos filosóficos y retóricos de la antigüedad romana, promovidas por este soberano y por el infante-regente don Pedro ${ }^{53}$.

La impronta en el Leal Conselheiro de los letrados cercanos al monarca no se limita a Cartagena. Para la comprensión del pensamiento ciceroniano de la prudencia, se transcribe posteriormente un texto escrito con esta finalidad por el doctor Diogo Afonso Mangancha, oficial y consejro $(1427-1447 ; \dagger 1448)^{54}$.

En definitiva, se puede advertir en la obra de don Duarte una proximidad entre la prudencia y significantes que consideramos oportuno resaltar: regimiento verdadero, señorío, recuerdo, memoria, consejo, recomendación, entendimiento, sabiduría, sutileza, imaginación, conciencia, acrecentamiento de

50 Campos Souto, Mar: Memorial de virtudes de Alfonso de Cartagena, Ayuntamiento de Burgos, 2004; BECEIRO PITA, Isabel, «La importancia de la cultura en las relaciones peninsulares (siglo XV», en Libros, lectores y bibliotecas..., pp. 191-194.

51 «[...] E das outras quatro, scilicet Prudència, Justiça, Temperança, Fortaleça, que por cristãos de todas maneiras, gentíos, judeus e mouros, que livros delas escreveram, são chamadas principais, é mui cumpridamente tratado em o livro de Regimento de Príncipes que compõs Frey Gil de Roma. E no Memorial das Virtudes que das Éticas de Aristóteles me ordenou o adião de Santiago [.... Leal Conselheiro, ed. cit., p. 248.

52 Leal Conselheiro, ed. cit., capítulo LV, pp. 277-280.

53 BECEIRO PITA, Isabel: «La recepción de la cultura aristocrática castellana en el Portugal de los Avís», en Estudos em homenagem ao professor doutor José Marques, Faculdade de Letras da Universidade do Porto, vol. 2, Porto, 2006, pp. 232-235.

54 Sobre este personaje, véase Freitas, Judite A. Gonçalves de: 'Teemos por bem e mandamos': A Burocracia Régia e os seus Oficiais em Meados de Quatrocentos (1439-1460), 2 vols., Cascais, Patrimonia, 2001, vol. I, p. 112-113. 
honra y estado, buena disposición, buen gobierno y buen contentamiento (regedoria verdadeira, senhorio, relembrança, avisamento, entendimento, sabedoria, subtileza, imaginação, consciência, acrescentamento de honra e estado, boa disposição, bom governo e bom contentamento). Se trata, por tanto, de un pequeño gran mundo léxico, que merece vastas indagaciones futuras.

\subsection{Consejo}

Es el vocablo de mayor número de incidencias, tanto en el Leal Conselheiro como, sobre todo, en el Livro dos Conselhos de el-Rei D. Duarte 55 .

Quien desprevenidamente aborde textos políticos de la Edad Media tardía portuguesa, puede sorprenderse con la dimensión polisémica del término consejo $^{56}$. Atendiendo al vocabulario significante del asesoramiento de los monarcas y teniendo en cuenta la documentación de la Chancelaría y eventuales paráfrasis cronísticas, el período comprendido aproximadamente entre 1380 y 1450 nos depara tres tipos de situaciones, como otros tantos círculos concéntricos, avanzando desde el más restringido al de mayor alcance:

Una fuente oficial regia o un texto cronístico puede relatar que el monarca hubo o tomó «conselho com...». Los personajes oídos pueden serlo «ad hoc» o integrar formalmente el consejo del rey. La mención a oír pareceres múltiples puede englobar ambos tipos de situaciones.

Pero otras veces los documentos aluden a alguien como «do seu conselho». Esto nos indica la configuración de un órgano colegial, con un elenco que, medio siglo después de la instauración de los Avís, fluctúa entre una decena y decena y media de componentes, puntualmente en representación estamental. Nunca parece reunirse en plenario. Antes bien, la nueva dinastía escucha o encarga algo a un número reducido de individuos ${ }^{57}$.

Por último, consejo puede aparecer en un contexto léxico significante de reunión — que avisa, recomienda y aconseja — de los tres «braços» del reino, las $\operatorname{cortes}^{58}$, y aquí tenemos la «totalidad nacional», a la que nos hemos referido en el título de este artículo, la totalidad nacional posible, entiéndase que la representación de las comunidades concejiles susceptibles de presencia, está concentrada ya en una élite de familias y de notables, que, en ocasiones, como

55 Para comenzar, desde luego, con los títulos de las diferentes subdivisiones de la obra.

56 Véase Homem, Armando Luís de Carvalho, 1987, «Conselho Real ou conselheiros do Rei ? A propósito dos «Privados» de D. João I», Revista da Faculdade de Letras [U. Porto]. História, II serie, IV (1987), pp. 9-68; reed. in IDEM, Portugal nos finais da Idade Média: Estado, Instituições, Sociedade Política, Lisboa, Horizonte, 1990, p. 221-278.

57 Homem, Armando Luís de Carvalho, Portugal nos finais da Idade Média (citado en la nota anterior), pp.. 236-246 y siguientes.

58 Véase Sousa, Armindo de: As Cortes Medievais Portuguesas (1385-1490), 2 vols., Porto, INIC/CHUP, 1990, especialmente las consideraciones conceptuales y léxicas del vol. I. 
sucede en Oporto a mediados del Cuatrocientos, no sobrepasan un $10 \%$ de la población urbana ${ }^{59}$.

Una investigación exhaustiva de las abundantísimas apariciones de estas y otras acepciones de «conselho» en los escritos del Elocuente desborda los límites de este trabajo. Hemos de quedarnos, por tanto, en las tres acepciones ya mencionadas, que quedan patentes en el Livro dos Conselhos ( considerando no sólo la autoría del propio don Duarte, sino también los consejos de terceras personas transcritos allí ${ }^{60}$. Allí se muestran los dos primeros significados y, a menudo, en un mismo texto, como puede observarse en el siguiente pasaje de la "Ordenança dos tempos em que auja de despachar, e como»:

Porque nos entendemos prazendo a nosso senhor deus que pera bom regymento destes reynos e de nosa casa he neçesario auer continuado e ordenado conselho pera o qual entendemos que seJa neçesario e cada hũ de meus Jrmãos seJa e el cabeça / Porende em sua presença ou sem eles seJa sempre onde quer que nos estyuermos $\mathrm{d}$ aseseguo [...] cada manhã [...] venham bem çedo todolos do conselho que em nosa casa forem e aly trautarom de todalas cousas que seram compridoiras por seruiço de nosso senhor deus e nosso e por honrra e proueyto destes reynos ${ }^{61}$.

Pero consejo puede igualmente aludir a lo que hoy llamaríamos parecer, facilitado por algún familiar del monarca o por sus oficiales, consejeros y privados. Este sentido se halla en los títulos de 11 capítulos $^{62}$. En la carta del conde de Arraiolos, aparece en diversos párrafos la expresión «este conselho», aludiendo al enviado al rey por este señor. En el "Conselho do conde d Ourem», la «Carta [...] do Jffante dom pedro a el rey seu Irmão quando foy aleuantado por Rey» o en el "Conselho espeçial d el rey dom Duarte ao Ifante dom anrrique seu Irmão quando foy sobre TanJer», este término equivale a opinión, modo de ver y actuar, como resultado de la audición de terceros por el monarca. En el primer caso puede leerse «d el rey non querer obrar por seu conselho como polo uoso» ${ }^{63}$, en el segundo se expresa esta idea en forma verbal — «a uantaJem de uos uerdadeyramente e com esguardo de todo nosso bem conselhar${ }^{64}$, mientras que en el tercer y último ejemplo queda especialmente de mani-

59 SousA, Armindo de: As Cortes Medievais (citado en la nota anterior); IDEM, «O Parlamento medieval portugués: perspectivas novas», Revista da Faculdade de Letras [U. Porto]. História, II sér., VII (1990), p. 47-58; IDEM, «Estado e comunidade: representação e resistências», en CoELHO, Maria Helena da Cruz; Homem, Armando Luís de Carvalho (Coord.): A Génese do Estado Moderno no Portugal Tardo-Medievo (séculos XIII-XV), Lisboa, Universidade Autónoma, 1999, p. 293-313.

60 Cuando hablamos de «capítulos» del Livro dos Conselhos, nos referimos a la numeración de las subdivisiones do texto que consta en la edición diplomática utilizada.

${ }^{61}$ Livro dos Conselhos, ed. cit., pp. 17-18.

62 Se trata de los capítulos $1,3,5,6,9,10,11,12,13,20$ y 21, pp. 7-11, 21-27, 40-43, 4350, 65-69, 69-71, 74-79, 79-82, 82-87, 116-121 у 121-125.

63 Livro dos conselhos..., capítulo 10, p. 71.

64 Livro dos conselhos..., capítulo 11, p. 74. 
fiesto el significado de consejo como opinión o juicio: «[...] que façais todos uosos feitos com bom conselho, e non por seguyr Vosa grande e boa uontade» ${ }^{65}$

\section{Conclusiones}

Aún cuando esta contribución consista en una muestra a pequeña escala, estimamos que, habida cuenta de la insistencia del Eloquente en el tratamiento de vicios, virtudes y sentimientos individuales, resulta suficiente puede mostrar que soberano luso constituye uno de los exponentes modernizantes del pensamiento político portugués del Cuatrocientos ${ }^{66}$, como actor principal de una praxis gobernante que subraya el imperio de la ley regia, una ley sistematizada, compilada y, como tal, fácilmente accesible a los oficiales de la justicia real, lo que refuerza esa idea del protagonismo eduardino en el proceso de la genésis de la modernidad política en Portugal.

El método seguido - el análisis léxico unido a la teoría de los campos semánticos- ofrece unas posibilidades al estudio de las ideas intelectuales y el pensamiento político bajomedieval que aún no han sido suficientemente explotadas. Sería aconsejable, por tanto, extender las indagaciones al resto del período de la dinastía Avís, tomando como base no sólo las fuentes documentales, crónicas y escritos de los titulares del poder, sino también los compendios y traducciones promovidas por éstos e, incluso, los escasos ejemplares conservados de las bibliotecas principescas.

Es más, la importancia de los contactos culturales entre los reinos de Portugal y Castilla durante toda la Edad Media lleva a pensar en la conveniencia de ampliar la búsqueda al conjunto del occidente peninsular, mediante un análisis comparado que permita esclarecer las similitudes y diferencias existentes en el pensamiento político de ambos países.

65 Livro dos conselhos..., capítulo 21, p. 127.

66 En contraste con el sentido arcaizante de la teoria del benefício feudal patente en la Virtuosa Benfeitoria del infante don Pedro, como se ha dicho, hermano del rey y futuro regente; el enraizamiento pleno de esta idea en la comunidad cliológica portuguesa llevará necesariamente a una revalorización de papéis e sentidos de actuaşão en la compleja coyuntura de finales de la década de 1440. 